\title{
PRÁTICAS DE ALEITAMENTO MATERNO EM UNIDADE DE TERAPIA INTENSIVA NEONATAL ${ }^{\mathrm{a}}$
}

\author{
BREASTFEEDING PRACTICES IN THE \\ NEONATAL INTENSIVE CARE UNIT ${ }^{\mathrm{a}}$
}

\section{PRÁCTICAS DE LACTANCIA MATERNA EN LA UNIDAD DE CUIDADOS INTENSIVOS NEONATALES ${ }^{\mathrm{a}}$}

\author{
Aisiane Cedraz Morais ${ }^{1}$ \\ Siena Nogueira Guirardi ${ }^{2}$ \\ Juliana de Oliveira Freitas Miranda ${ }^{3}$
}

Como citar este artigo: Morais AC, Guirardi SN, Miranda JOF. Práticas de aleitamento materno em unidade de terapia intensiva neonatal. Rev baiana enferm. 2020;34:e35643.

Objetivo: analisar as formas de aleitamento materno realizadas na Unidade de Terapia Intensiva Neonatal e identificar suas facilidades e dificuldades. Método: estudo qualitativo e descritivo, numa Unidade de Terapia Intensiva Neonatal de maternidade pública. Os dados foram coletados por meio de entrevista semiestruturada e observação direta entre fevereiro e março de 2017. Foram entrevistados cinco profissionais de saúde e sete mães. Resultados: emergiram três categorias: Compreensão das mães e profissionais sobre o conceito e a importância do aleitamento materno; Formas de aleitamento materno na voz de mães e profissionais de saúde; e Interferências para a realização do aleitamento materno. Conclusão: na prática do aleitamento materno no contexto da Unidade de Terapia Intensiva Neonatal existem algumas dificuldades que são atenuadas pela presença de fonoaudiólogo, parceria do banco de leite e atuação dos profissionais de saúde. As pessoas têm dificuldade em definir o aleitamento materno e o relacionam exclusivamente com a amamentação.

Descritores: Aleitamento Materno. Terapia Intensiva Neonatal. Cuidado do Lactente.

Objective: to analyze the forms of breastfeeding performed in the Neonatal Intensive Care Unit and to identify its facilities and difficulties. Method: qualitative and descriptive study, in a Neonatal Intensive Care Unit in a government maternity. Data were collected through semi-structured interviews and direct observation between February and March 2017. Five health professionals and seven mothers were interviewed. Results: three categories emerged: Understanding of mothers and professionals about the concept and importance of breastfeeding; Forms of breastfeeding in the voice of mothers and bealth professionals; and Interferences for breastfeeding. Conclusion: in the breastfeeding practice in the context of the Neonatal Intensive Care Unit, there are some difficulties mitigated by the presence of a speech therapist, partnership with the milk bank and the performance of health professionals. People have difficulty to define breastfeeding and relate it to exclusive breastfeeding.

Descriptors: Breast Feeding. Intensive Care, Neonatal. Infant Care.

\footnotetext{
a Trata-se de um recorte do Trabalho de Conclusão do Curso intitulado "Práticas de aleitamento materno em unidade de terapia intensiva neonatal", defendida na Graduação de Enfermagem da Universidade Estadual de Feira de Santana, Bahia, em 2017.

Enfermeira. Doutora em Enfermagem. Professora Adjunta da Universidade Estadual de Feira de Santana. Feira de Santana, Bahia, Brasil. aisicedraz@hotmail.com. http://orcid.org/0000-000 I-9547-69| 4.

2 Enfermeira. Especialista em Saúde da Família. Especialista em Enfermagem Pediátrica e Neonatal. Pesquisadora independente. Feira de Santana, Bahia, Brasil. http:// orcid.org/0000-0002-6562-9382.

3 Enfermeira. Doutora em Enfermagem. Professora Adjunta da Universidade Estadual de Feira de Santana. Feira de Santana, Bahia, Brasil. http://orcid.org/0000-000 I 7659-3103.
} 
Objetivo: analizar las formas de lactancia materna realizadas en la Unidad de Cuidados Intensivos Neonatales e identificar sus facilidades y dificultades. Método: estudio cualitativo y descriptivo, en una Unidad de Cuidados Intensivos Neonatales en una maternidad pública. Los datosfueron recopilados mediante entrevistassemiestructuradas $y$ observación directa entre febrero y marzo de 2017. Fueron entrevistados cinco profesionales de la salud y siete madres. Resultados: surgieron tres categorias: Comprensión de madres y profesionales sobre el concepto y la importancia de la lactancia materna; Formas de lactancia materna en la voz de madres y profesionales de salud; e Interferencias para la lactancia materna. Conclusión: en la práctica de la lactancia materna en el contexto de la Unidad de Cuidados Intensivos Neonatales, existen algunas dificultades mitigadas por la presencia de un logopeda, la asociación con el banco de leche y el desempeño de los profesionales de salud. Las personas tienen dificultad para definir la lactancia materna y la relacionan exclusivamente con amamantamiento.

Descriptores: Lactancia Materna. Cuidado Intensivo Neonatal. Cuidado del Lactante.

\section{Introdução}

O aleitamento materno é a maneira mais eficaz de alimentar uma criança, por atender os aspectos nutricionais, imunológicos e psicológicos, protegendo-a de diversos riscos de saúde ${ }^{(1-2)}$. Conceitualmente, o aleitamento materno é o ato de a criança receber o leite materno (direto da mama ou extraído), independentemente de receber ou não outros alimentos, enquanto que o aleitamento materno exclusivo é quando o recém-nascido $(\mathrm{RN}) /$ lactente recebe o leite humano materno sem complemento líquido ou sólido de outro alimento ${ }^{(3)}$.

No senso comum, quando se refere ao aleitamento materno, associa-se ao ato da sucção à mama. Entretanto, a prática do aleitamento possibilita outras formas de ofertar o leite humano, incluindo a amamentação - sucção à mama materna ou a extração manual de leite (oferecido por seringa ou gavagem) e a translactação ${ }^{(4)}$.

Mesmo tendo o conhecimento a respeito da importância do aleitamento materno, esse ainda é um desafio para os profissionais de saúde, principalmente para os que trabalham em unidades de terapia intensiva neonatal (UTIN) $^{(1)}$. Existem fatores que contribuem para que as mães sejam desencorajadas a amamentar/extrair manualmente, como a falta de informações, a falta do contato precoce com o recém-nascido, a ansiedade e a separação devido às condições do bebê, a falta de conhecimento referente às vantagens do aleitamento para ambos e, principalmente, a falta de incentivo à participação da mãe na recuperação do seu filho através dessa ação ${ }^{(1,5)}$.
Com o internamento do RN na UTIN, o contato físico com a mãe torna-se limitado; surgem os sentimentos de frustração, insegurança, preocupação, ansiedade e falta de confiança na capacidade de cuidar do seu filho e a participação da mãe na assistência é mínima, somados à necessidade de suportes como oxigênio, ventilação mecânica ou outras vias alternativas de alimentação. Esses fatores afetam diretamente o processo do aleitamento materno na UTIN $^{(5-6)}$.

Diante desse contexto, é importante o estabelecimento de vínculos que tornem a relação entre os profissionais e as mães mais sólida, estimulando a troca de informações, orientações e apoio, fatores fundamentais para que o aleitamento seja estimulado e ocorra de maneira eficaz e tranquila. Entretanto, essas práticas nem sempre são realidade no serviço, devido à rotina e até ao despreparo dos profissionais que prestam a assistência ${ }^{(4)}$.

Diante dessa realidade, surge uma indagação: Como acontece a prática do aleitamento materno no contexto de uma UTIN? Quais as formas de aleitamento utilizadas na UTIN?

Assim, tem-se como objetivo: Analisar as formas de aleitamento materno realizadas na UTIN e identificar as facilidades e/ou dificuldades para o aleitamento materno no contexto da UTIN.

\section{Método}

Trata-se de estudo descritivo, com abordagem qualitativa, fundamentada na análise de 
conteúdo de Bardin. A escolha da abordagem qualitativa se justifica por ser capaz de englobar o significado e a intencionalidade como próprios aos atos, às relações e às estruturas sociais, tendo enfoque em situações subjetivas e particulares que contribuíram para a compreensão do aleitamento materno de recém-nascidos internados em unidade de terapia intensiva neonatal, bem como a dinâmica e a estrutura da situação sob o ponto de vista de quem vivencia ${ }^{(7)}$.

A pesquisa foi desenvolvida em uma maternidade pública, de um município do interior da Bahia, credenciada como Hospital Amigo da Criança, que possui banco de leite próprio e é maternidade de referência para os municípios vizinhos.

Os participantes da pesquisa foram cinco profissionais que trabalhavam na unidade por pelo menos um ano, e sete mães de recém-nascidos internados por pelo menos uma semana sem contraindicação para o aleitamento materno. Os profissionais foram sinalizados pela coordenação do setor e as mães pela enfermeira supervisora do dia. Anteriormente à entrevista, foi esclarecido aos participantes sobre a pesquisa e a condição obrigatória de assinar o Termo de Consentimento Livre e Esclarecido (TCLE). Após a assinatura do TCLE, prosseguiu-se com a coleta de dados.

A coleta de dados foi realizada mediante observação direta e entrevista semiestruturada, composta por perguntas abertas e fechadas que possibilitavam um diálogo mais livre, sem a necessidade de seguir rigorosamente as questões ${ }^{(7)}$.

Os dados foram analisados com base na Análise de Conteúdo, conjunto de técnicas de análise das comunicações, que tem como finalidade o levantamento de indicadores que permitam a realização da inferência de conhecimentos. Essa técnica desdobra-se nas seguintes etapas: pré-análise, exploração de material, tratamento dos dados, inferência e a interpretação deles ${ }^{(8)}$.

O projeto de pesquisa foi submetido à apreciação e análise do Comitê de Ética em Pesquisa (CEP) da Universidade Estadual de Feira de Santana (UEFS), e aprovado sob o Parecer n. 1.841.286 e CAAE 59493416.0.0000.0053. No seu desenvolvimento foram seguidas as orientações, normas e recomendações éticas para a realização de pesquisa com seres humanos no Brasil, conforme Resolução n. 466/2012 ${ }^{(9)}$. O anonimato dos participantes foi garantido com a utilização de codinomes de flores para os profissionais e pedras preciosas para as mães.

O período de coleta de dados foi de fevereiro a março de 2017. A observação direta sistemática acontecia no turno da manhã ou da tarde, de acordo com a disponibilidade da pesquisadora, incluindo sempre um dos horários de oferta do leite materno (9-12-15-18) pré-estabelecido na rotina da unidade. As observações aconteciam com roteiro estruturado, em tempo mínimo de duas horas e máximo de quatro horas. Foi possível realizar 24 períodos de observação e todos os dados desta técnica foram registrados em diário de campo.

As entrevistas aconteceram em sala reservada, autorizada previamente pela coordenação do setor. As falas foram gravadas em gravador e posteriormente transcritas. Na exploração do material as falas convergentes foram agrupadas.

\section{Resultados e Discussão}

Com relação às mães, 4 eram primíparas e 3 multíparas; a idade variou entre 19 e 38 anos; 2 eram solteiras e 5 casadas. Com relação aos $\mathrm{RN}, 4$ eram prematuros e 3 a termos, e todos possuíam o leite materno exclusivo como dieta.

No que diz respeito aos profissionais, a idade variou entre 34 e 46 anos, sendo 1 enfermeira, 2 técnicos de enfermagem, 1 fisioterapeuta e 1 fonoaudiólogo; 3 possuem filhos e 2 não (e desses, todos realizaram aleitamento materno); o tempo de atuação na UTIN variou entre 2 e 17 anos; e o tempo de formação entre 7 e 9 anos.

As três categorias de análise que emergiram dos dados - Compreensão das mães e profissionais sobre o conceito e a importância do aleitamento materno; Formas de aleitamento materno na voz de mães e profissionais de saúde; e Interferências para a realização do aleitamento materno no contexto da UTIN - são apresentadas na sequência: 
Compreensão das mães e profissionais sobre o conceito e a importância do aleitamento materno

Aleitamento materno exclusivo é a oferta do leite humano direto da mama ou extraído manualmente $e^{(10-11)}$. No entendimento dos profissionais, esse conceito encontra-se um pouco confuso, evidenciando a dificuldade para definir aleitamento materno, fato que corrobora eventuais achados na literatura, que não diferencia a amamentação do aleitamento, como é demonstrado na fala a seguir:

Aleitamento materno é... quando o bebê nasce, a gente tenta colocar no peito... porque é a primeira vacina, por causa do colostro e... assim... como é que eu vou falar... que é tão normal pra gente que a gente não sabe como falar... é o começo, né? (Girassol).

Chama atenção o fato do aleitamento materno, por ser uma prática tão comum e cotidiana, não ser elaborado conceitualmente de forma correta pela maioria dos profissionais e, muitas vezes, confundida com a amamentação.

No que se refere ao entendimento das mães, percebe-se a limitação das informações passadas durante o pré-natal, bem como o conhecimento referente ao tema, fato que acaba restringindo esse entendimento ao que é divulgado através do senso comum.

Eu entendo assim, é sobre dar mama ao bebê, essas coisas assim. Eu entendo isso só... (Esmeralda).

O que eu entendo por aleitamento materno, o que eu aprendi de tanto as pessoas falarem. (Brilhante).

Nesse sentido, os tabus e as crenças contribuem para a construção do saber, sendo a herança sociocultural determinante para os diferentes significados do aleitamento materno para a mãe $e^{(12-13)}$.

Entretanto, fica evidente nas falas de mães com maior escolaridade, a busca por informações relacionadas ao aleitamento materno, ainda que o associem à amamentação:

Ab, eu acho muito importante, né, pra criança ter uma vida saudável, desde a gravidez eu procurei ler bastante pra poder amamentar e se conseguir, poder fazer até doação também. Porque realmente com ela eu pretendo até, pelo menos, o sexto mês só amamentação e depois a introdução de alimento como o pediatra provavelmente deve me orientar. (Pérola).
Essa fala demonstra um conhecimento relacionado à amamentação, o que pode associar-se ao fato de serem as únicas mães entrevistadas com escolaridade de nível superior, o que as possibilita falar com mais propriedade sobre esse tema, englobando inclusive os seus benefícios.

Aleitar - para além de nutrir a criança favorece a criação do vínculo mãe-bebê, melhora a imunidade do bebê, protege contra infecções e também repercute no seu desenvolvimento emocional e cognitivo e contribui na saúde física e psíquica da mãe ${ }^{(10,14)}$. Para a maioria dos profissionais, o aleitamento traz os benefícios apontados pelo Ministério da Saúde, como é evidenciado nas falas a seguir:

E pra mãe, ajuda na melhora do organismo da mãe, protege contra o câncer, ajuda a perder peso, aumenta o vínculo mãe e filha, é importante pra mãe tá conbecendo o bebê, a troca dos olhares do bebê... (Rosa).

Os benefícios citados pelos entrevistados convergem com a literatura, uma vez que a amamentação pode, imediatamente após o parto, estimular o desenvolvimento de vínculo afetivo entre a mãe e o recém-nascido, prevenir sangramentos e anemia pelo aumento de liberação da ocitocina e sensação de bem-estar pela beta endorfina, que são liberadas desde a primeira sucção, contribuir com a perda de gorduras acumuladas durante a gestação, prevenir câncer de mama e de ovário pela presença dos macrófagos no leite materno, e aumentar os espaços entre as gestações e partos ${ }^{(14-16)}$.

Além dos benefícios maternos, o leite humano está adequado às necessidades do lactente. Desta maneira, a composição do leite materno, fornecido pela própria mãe, possui valores nutricionais conforme a necessidade do recém-nascido, de acordo com a idade gestacional, fato que traz benefícios para o RN, como a proteção contra diarreia infecciosa, otites e infecções respiratórias, melhora do desenvolvimento neurológico, além de proteção contra diversas patologias, pelo fato de possuir imunoglobulinas que são passadas para o $\mathrm{RN}^{(2)}$.

Aleitamento materno é... além de simplesmente forma de alimentação do bebê, é tudo aquilo que engloba o aleitamento em si... interação com a mãe, criação de vínculo, é... a alimentação por si só, a melhor forma de 
desenvolvimento do bebê e... o primeiro... logo quando o bebê nasce, a primeira coisa que nós fazemos é colocar o bebê no peito então é a primeira forma que o bebê tem de contato com a vida. (Lírio).

Assim, os profissionais pontuam vários benefícios do leite materno para o bebê, que também são apontados pelas mães entrevistadas. É perceptível também o conhecimento que as mães têm em relação aos benefícios do aleitamento materno para o bebê, além da importância da criação do vínculo entre mãe e bebê, como mostram as falas de Turquesa e Brilhante:

Seria mais saudável ter muito contato da mãe com o filbo que ele desenvolve mais rápido e seria muito bom, né, seu próprio filho tomar seu próprio leite da mãe. (Turquesa).

Pelo leite eu passo pra meu filbo tudo que eu sinto, as minhas emoçôes e através dele é a maior fortaleza, por exemplo, quando tá doente, pra tudo, entendeu? Pra curar. É o maior vínculo entre ele e a mim, que quanto mais eu dá mama a ele, aí mais a gente vai tá ligado por mais tempo, é o que eu entendo. (Brilhante).

As situações evidenciadas nessa categoria permitiram compreender que apesar das pessoas possuírem conhecimentos pertinentes e importantes a respeito dos benefícios do leite humano para os recém-nascidos e para as mães, ainda é necessário um aprofundamento e melhor conhecimento no que diz respeito ao entendimento do aleitamento materno, uma vez que este ainda é muito confundido com a amamentação e vice-versa.

Além disso, é fundamental que os profissionais se aprofundem no estudo da temática, para que, além de adquirir o conhecimento da definição dessa prática, ainda sejam capazes de transmitir esse conhecimento correto para as mães, a fim de esclarecer dúvidas e promover a prática, enfatizando os benefícios e a sua importância.

\section{Formas de aleitamento materno na voz de mães e profissionais de saúde}

O aleitamento materno é o uso do leite humano (doadora ou mãe), fornecido à criança por diversas formas (copinho, cateter gástrico, mamadeira, por exemplo) ${ }^{(5,17)}$. Entretanto, no senso comum, o aleitamento materno é imediatamente associado à amamentação (sucção à mama).
Percebe-se na fala dos profissionais entrevistados, a associação do aleitamento materno com a amamentação:

Eu entendo como aleitamento materno, o aleitamento materno mesmo, propriamente dito, o contato do bebê com o peito da mãe, entendeu? É só essa, uma forma só. (Lírio).

As formas de aleitamento materno? Só mãe e filho mesmo, é indo pro peito. (Girassol).

Entende-se que essa associação ocorre pelo fato de certas literaturas referirem-se ao aleitamento materno como a amamentação exclusivamente e, dessa maneira, as pessoas não se aprofundam sobre essa temática, por ser bastante comum e, consequentemente, limitam a compreensão do que seja o aleitamento materno.

Ainda, o aleitamento ${ }^{(4)}$ feito pela mãe é realizado por meio da amamentação, isto é, pela sucção direta da mama. Alguns profissionais, quando dialogando sobre a prática do aleitamento realizada na UTIN, referem-se exclusivamente à prática da amamentação:

\begin{abstract}
A prática do aleitamento materno é feita nos bebês que não tem ventilação... os bebês que tão em ambiente, sem ventilação nenhuma... eles fazem o contato com a mãe, a gente... a mãe pega ou a gente pega, coloca no peito da mãe, sendo que aqui a gente tem ofonoaudiólogo pra tá intervindo e ajudando a gente nisso. (Lírio).

O médico avalia o quadro, quando pode colocar no peito, ele coloca no prontuário e chama o fono, aí o fono veme coloca no peito. Mas a gente segue alguns parâmetros de peso, de semanas, de estado clínico... ele avalia e a gente também. (Girassol).
\end{abstract}

Não obstante alguns profissionais citarem as diversas formas de aleitamento materno, inclusive as que ocorrem na UTIN e fazem parte do seu cotidiano de trabalho, não associam que essas condutas são práticas de aleitamento materno, como a alimentação por copinho ou por gavagem, e ainda a extração manual:

E tem os horários que elas vão vir praqui e vão fazer a ordenha. (Rosa).

Logo quando chega, geralmente é via sonda, né?! Porque ainda não tem a sucção, aí com o passar do tempo, é... a fonoaudióloga vai fazendo os testes aí quando começa a ter sucção boa, aí tira a sonda e começa a... se a mãe tiver ordenhando bem a quantidade de leite, ai coloca no peito dela, se não a gente faz via oral. (Cravo).

A gente trás o copinho pra ela, estéril, ela tira o leite aquela quantidade que tá prescrita que tem que tomar, né[...] Se ela não tiver condições de tirar o leite, eu posso tirar, 
oferecer no copinho, né, ou na seringa... Então a gente procura as vias de oferecer pra ele no momento que ele precisa, o leite materno. (Orquídea).

Pode-se perceber que, até pelo tempo que se encontram na UTIN, as mães acabam conhecendo um pouco mais sobre as formas de aleitamento materno, se referindo também às práticas citadas pelos profissionais, como mostram as falas a seguir:

\footnotetext{
Ele no começo, ele não tomava, porque saia um liquidozinho, uma sujeirinha de dentro dele. Ai quando ele começou a tomar, ai enchia no copinbo, ela bota na seringa e coloca no caninbo, que eu acho que o nome daquele negócio é sonda. Ele recebe direitinho. (Rubi).

Depende... se a mãe não tiver leite, tem outras formas de aleitar o bebê, essas coisas... o leite doado do banco [...] Que a gente dá pela sonda [...] Ela tava recebendo pela sonda. (Esmeralda).
}

Ainda que não seja uma prática de aleitar, a extração manual consiste em uma das etapas do aleitamento e foi referenciada tanto pelas mães quanto pelos profissionais, pois, por meio dela é possível obter o leite humano, seja ele ofertado diretamente da mãe para seu filho ou processado no Banco de Leite Humano e direcionado posteriormente para o bebê.

Com a extração manual do leite, há possibilidades de oferta do leite humano ao RN, como a alimentação por copinho, técnica que consiste em oferecer o leite ao bebê com o copo, estimulando o movimento da língua e sua mandíbula $^{(4)}$. A alimentação por gavagem é realizada por meio de uma sonda, normalmente orogástrica, e o leite é administrado por meio da ação da gravidade, bem lentamente ${ }^{(2)}$.

A gastróclise - gavagem contínua, utilizando a seringa em bomba de infusão - só é indicada em casos de intolerância à gavagem intermitente ou em RN muito pequeno, que não tolera o volume de uma só vez ${ }^{(2)}$. Essa prática foi citada por Esmeralda para referir a forma de oferta do leite humano para seu filho:

Aí depois do que aconteceu com ela, ela agora tá tomando pela bomba, mas na sonda ainda, só que em um processo mais devagar pra ela se acostumar com o leite. (Esmeralda).

Além das formas de aleitamento citadas, tem-se a translactação, que consiste na oferta do leite humano por meio de uma sonda conectada a uma seringa, com a outra extremidade fixada no mamilo ou no dedo do profissional, para que seja introduzida na boca do RN. Essa prática não foi observada durante a coleta de dados, entretanto, consiste na técnica ${ }^{(18)}$ mais eficaz para favorecer a transição da alimentação alternativa por sonda gástrica para a via oral quando comparada a outros métodos, pois é o meio pelo qual o recém-nascido prematuro (RNPT) recebe estímulos orais fidedignos em virtude de ser exposto diretamente à mama materna ${ }^{(4)}$.

\section{Interferências para realização do aleitamento materno no contexto da UTIN}

O aleitamento materno no contexto da UTIN tem importância clínica na medida em que sua resposta interfere diretamente nas condições do bebê, seja na sua evolução positiva ou não. Assim, faz parte da prescrição médica diária qual o tipo de leite, via de administração, volume e intervalo entre as dietas e, consequentemente, torna-se um cuidado cotidiano realizado pela equipe de enfermagem. Por outro lado, percebe-se que não há um estímulo para a amamentação, que é vista como um cuidado primário e se apresenta como um processo complexo, que merece atenção tanto da enfermagem como da rede de apoio social à nutriz, para que seja possível concretizar o aleitar à mama e o aleitamento materno após alta hospitalar ${ }^{(13,18-19)}$.

O fato de não entender o aleitamento materno como a ampla prática interfere no momento de elencar as dificuldades em realizá-lo, referindo apenas a situação clínica em que o recém-nascido se encontra como um impeditivo:

Dificuldade a gente não tem nenbuma... dificuldade, que a gente não chama de dificuldade, é em virtude do quadro clínico do paciente [...] No que depender da gente, a nivel de equipe, não tem dificuldade nenbuma. (Lírio).

Conforme a fala acima, percebe-se que a única dificuldade estava na condição clínica do bebê, pelo fato desses profissionais associarem o aleitamento materno exclusivamente à amamentação. Dessa maneira, o RN que se encontra instável, em uso de ventilação mecânica, em uso 
de medicamentos depressores do sistema nervoso central, com baixo peso, não se encontra em condições de realizar a sucção à mama.

Além das dificuldades relacionadas à condição clínica do RN, existem as relacionadas às mães, uma vez que estas se encontram em ambiente estranho, sob muita tensão, ansiedade e medo; tem o fato de não querer aleitar ou intercorrências mamárias que podem ocorrer como o ingurgitamento, pelo fato de o RN não estar mamando e não ser realizada a extração manual adequada e frequentemente ${ }^{(18-19)}$.

Como a decisão de realizar o aleitamento materno é exclusivamente da mãe, esse assunto deve ser esclarecido desde o pré-natal, momento em que a mulher dá entrada na Unidade Básica de Saúde (UBS) para este fim, desde a primeira consulta. Além disso, recomenda-se também a realização de ações educativas sobre aleitamento materno, para propiciar melhor aprendizado sobre o tema, bem como, além de informações teóricas, realizar práticas com bonecas e compartilhar informações escritas para serem referências posteriormente ${ }^{(15)}$.

Quando as mamas ficam muito cheias, né, turgidas, então na hora de tirar, dói. Então a dor faz com que ela desista de amamentar [...] agora assim, quando chega num determinado momento a gente vê o cansaço bater, né? [...] Mas o cansaço em si, as vezes elas... o cansaço as vezes elas não querem vim, né... Então é assim, mas a parte física delas, o emocional delas, muitas vezes elas tão com problema em casa, que a gente sabe disso, com o marido, então as vezes interfere, né, o leite some [...] Tem horas que elas ficam rebeldes... na bora de dormir, ai chegam de cara feia, mas... seu filbo que tá lhe chamando. (Orquídea).

A fala anterior aponta as diversas dificuldades que as mães enfrentam no contexto da UTIN para garantir a oferta do leite materno: esgotamento físico e psicológico, demandas familiares, estresse pelo próprio internamento, informações insuficientes para o processo da amamentação, além da resistência para esse processo.

As maiores dificuldades apresentadas pelas mães de RN internados na UTIN são ingurgitamento mamário, dor nos mamilos e diminuição do volume de leite. O ingurgitamento mamário é a distensão do tecido provocado pela retenção láctea nos alvéolos, consequentemente as mamas ficam doloridas e cheias, aumentando o fluxo sanguíneo no local, e, como o bebê não está sugando, se não realizar uma extração manual frequente e eficaz, a mama fica ingurgitada. Além disso, a dor mamilar ocorre pelo fato de os mamilos possuírem um tecido bastante sensível, facilmente irritado, podendo ocorrer lesões, o que dificulta ainda mais o processo de amamentação ou de extração manual do leite ${ }^{(2)}$.

As mães, em sua maioria, referem mais dificuldades em relação à produção de leite e ao estado do RN, como é evidenciado nas falas, e está em concordância com a literatura que afirma que a produção do leite diminui pelo fato de o bebê não estar sugando a mama, caso não haja estimulação regular e eficiente por meio da extração manual ${ }^{(4)}$.

As vezes a dificuldade é não ter o leite e assim, no caso,
como o bebê não tá mamando no seu peito, as vezes,
para de sair, as vezes o estresse com tudo que acontece,
vai acabando o leite, essas coisas... (Esmeralda).

Interfere, primeiro porque a gente não tem esse contato direto com a criança, aí eu acho que dificulta. (Diamante).

É possível perceber a dificuldade que as mães referem no que diz respeito à produção de leite. Esse fato pode ser relacionado à falta de orientação necessária para o início da extração manual logo nas primeiras horas após o nascimento, além da frequência e regularidade dessa técnica, uma vez que o RN não estará sugando à mama para estimular essa produção láctea. $\mathrm{O}$ fator emocional associado ao estresse pelo internamento do filho também colabora para a baixa produção láctea.

Para que a prática do aleitamento materno na UTIN tenha sucesso, é fundamental que a equipe tenha preparo técnico-científico sobre o tema para fornecer apoio e orientações claras e pertinentes às mães que se encontram nessa situação ${ }^{(1)}$. Isso é exposto na fala da mãe, a seguir:

\footnotetext{
No meu aver, assim, eu acho que nesses lugares de UTI, assim nesses lugares que a gente fica, tem que ser pessoas que já tenham que vir com um treinamento assim, pra dizer: "olhe, você vai ter que ser assim, carinhosa, paciente..." É como se fosse uma pessoa assim com dom, entendeu? Porque isso é muito importante. (Brilhante).
}

Percebe-se uma referência ao preparo profissional, que está em concordância com a literatura, pois autores afirmam que um dos pontos 
que contribuem para o insucesso do aleitamento materno é a falta de consistência nas informações passadas pelos profissionais, além da atitude da equipe em relação a essa prática e à falta de incentivo da participação da mãe ativamente pelos profissionais ${ }^{(2)}$.

Não obstante a ênfase ser sempre maior nas dificuldades, devemos levar em consideração algumas facilidades citadas e outras observadas com relação à realização da prática do aleitamento materno no contexto da UTIN.

Uma das facilidades citada é a presença do Banco de Leite Humano (BLH) no hospital, fato que favorece a obtenção de leite doado para o RN quando a mãe não consegue retirar manualmente o volume prescrito ou tem restrição, bem como a complementaridade do leite que foi retirado pela mãe em pouca quantidade. O BLH é responsável pela coleta, preparo, armazenamento e distribuição desse leite ${ }^{(16)}$.

Um ponto muito importante, que não foi referido nas falas, porém observado pela pesquisadora, é a presença materna diariamente ao lado do RN, que apesar de ser garantido por lei, não ocorre em todos os hospitais. Dessa forma, há uma facilidade em estimular a mãe a realizar/ colaborar com as práticas do aleitamento materno, além de facilitar a promoção do vínculo mãe/filho, independente das condições clínicas do bebê. Como subcategoria, foi estabelecida as Estratégias da equipe para incentivo do aleitamento materno, uma vez que esse aspecto ficou bem evidente.

\section{Estratégias da equipe de saúde para incentivo ao aleitamento materno}

É importante a valorização e o incentivo ao aleitamento materno pelos profissionais de saúde para que as mães entendam a importância do seu leite para o recém-nascido e percebam que ele ajuda no crescimento e desenvolvimento do RN, além de fortalecer o vínculo entre eles ${ }^{(12)}$.

Algumas intervenções podem ser realizadas para promover o aleitamento, como estabelecer rotinas que promovam e apoiem o aleitamento materno, orientar as mães de prematuros ou $\mathrm{RN}$ que não tenham condições de amamentar a iniciar a extração manual do leite, iniciar a dieta (leite materno) via gavagem o mais precocemente possível, iniciar a amamentação tão logo as condições do $\mathrm{RN}$ permitirem, promover $\mathrm{O}$ contato pele a pele com a mãe sempre que possível, fornecer informações quanto à realização da extração manual, bem como mostrar-se presente e disponível para conversar e esclarecer possíveis dúvidas. Para que essas intervenções sejam eficazes e coerentes, faz-se necessário uma equipe treinada e preparada no processo de aleitamento materno ${ }^{(2)}$.

Alguns elementos são fundamentais no apoio ao aleitamento materno como o aconselhamento, a escuta ativa, levar em consideração a escolha da mãe, estar disponível para responder as dúvidas sem fazer nenhum tipo de julgamento, oferecer informações e orientações referentes ao aleitamento e às técnicas adequadas ${ }^{(14)}$.

\begin{abstract}
A gente passa pra ela a importância que é o aleitamento materno. Então a gente fala, "mãe a gente precisa desse leite, se ele nasceu de 6 meses, esse leite que você vai produzir é o leite que a gente vai oferecer [...]" a gente vem incentivando, e aí a gente vai falando da economia que ela vai fazer depois que sair daqui, quanto ao artificial, o vinculo mãe e filho [...] a equipe toda aqui já é... a gente já tem aquela preparação da importância que éo leite materno [...] A gente orienta na enfermaria a tirar o excesso do leite, né, a massagear [...] Acho que é mais conversa mesmo... falar pra elas da importância, o diálogo... eu acho que deve ser acolhida no primeiro momento que elas tão chegando pra gente... porque assim, o que elas querem é o filho delas, então pra que você tenha seu filho, você tem que colaborar que é tirando o leite na hora certa. (Orquídea).
\end{abstract}

A fala dos profissionais representa a riqueza de como a equipe pode estimular as mães para o aleitamento materno, resgatando inclusive a importância da interação com as mães, da conversa e das orientações dadas para que a prática do aleitamento aconteça de forma plena e tranquila, principalmente no contexto da UTIN, por ser um setor de alto risco, em que os RN se encontram em situações mais graves.

Entretanto, quando se trata das mães, é perceptível a fragilidade nas formas de incentivo e nas estratégias utilizadas para aumentar o uso dessa prática na UTIN:

As formas de incentivo é sempre assim, beber água, as vezes pelo que a mãe tá passando, manda se acalmar, 
porque se não o leite vai embora, essas coisas... Quem mais incentiva... as técnicas que fica tomando conta do bebê no dia, depende da técnica, algumas sim, outras não. (Esmeralda).

Quando se analisa a fala dos profissionais e das mães à luz da literatura, observa-se certa contradição, uma vez que as mães não referem todas as estratégias que os profissionais dizem realizar. Além disso, percebe-se também a falta de conhecimento dos profissionais quanto às maneiras de incentivo que a literatura aponta, para que a prática do aleitamento materno seja mais realizada nesse ambiente, acabando por sempre oferecer as mesmas informações.

Outro fator importante no que se refere às estratégias utilizadas pela equipe para o incentivo à prática do aleitamento materno é o seguimento dos "Dez passos para o sucesso do aleitamento materno" (20) , como referem as falas dos profissionais a seguir:

\begin{abstract}
Desde o momento que a mãe chega, quando a mãe dá entrada no bospital, já começa a se falar do aleitamento materno. A gente é o hospital amigo da criança, aí desde que a mãe dá entrada no hospital já começa a se falar pra ela do aleitamento materno [...] Toda criança que ela não tá em ventilação, que ela tá estável, a gente incentiva a colocar no peito e as que estão em ventilação, a gente orienta as mães a irem no banco de leite, porque se não as mamas ficam ingurgitadas. (Lírio).
\end{abstract}

O aleitamento é... aqui é... dá um show, porque é o bospital amigo da criança. (Girassol).

O título "Hospital Amigo da Criança" que aparece nas falas acima, refere-se à iniciativa criada pelo Fundo das Nações Unidas para a Infância (UNICEF) juntamente com a Organização Mundial da Saúde (OMS), que tem como principal finalidade promover, apoiar e proteger o aleitamento materno, preservando o direito da mulher realizar essa prática de maneira segura e com sucesso. Um dos critérios globais da Iniciativa Hospital Amigo da Criança (IHAC) é a implantação e adesão aos "Dez passos para o sucesso do aleitamento materno" que são extremamente úteis no preparo da equipe e no fornecimento de orientações às mães ${ }^{(21-22)}$.

Essa categoria nos permite identificar que muitas são as dificuldades para a realização do aleitamento materno na UTIN, principalmente pelas condições maternas. Entretanto, é importante salientar as facilidades existentes, uma vez que há o incentivo por parte da equipe, bem como o suporte do banco de leite no contexto da UTIN e a possibilidade das mães amamentarem dentro do setor. Foi possível também destacar as estratégias que a equipe de saúde adota para incentivar o aleitamento materno, ainda que fique clara a necessidade de compreensão desse processo por parte das mães.

Salienta-se que este estudo tem por limitação não envolver a equipe do Banco de Leite, assim como a Gestão e/ou Coordenação Médica e de Enfermagem, o que poderia ampliar as discussões sobre essa temática.

\section{Conclusão}

Este estudo descreve, na ótica de profissionais e mães, a importância do aleitamento materno no contexto da unidade de terapia intensiva neonatal, bem como as práticas realizadas nesse setor. Percebe-se que as pessoas ainda têm dificuldade em definir o aleitamento materno e, em sua maioria, o relacionam exclusivamente com a amamentação; inclusive os profissionais de saúde revelam uma visão restrita dessa prática. Dessa forma, as práticas de aleitamento materno, citadas tanto pelos profissionais de saúde quanto pelas mães, foram a amamentação, a gastróclise, a gavagem, a translactação e a oferta do leite ordenhado no copinho.

Entretanto, evidenciam-se os benefícios do aleitamento materno para todos os indivíduos entrevistados, referidos tanto para o recém-nascido quanto para as mães, assim como para o estabelecimento do vínculo entre eles.

Confirma-se a existência das dificuldades no que se refere à realização da prática do aleitamento materno na UTIN, principalmente em relação ao conhecimento das mães referente ao tema, aos problemas que surgem nas mamas pelo fato de não serem estimuladas e esvaziadas adequadamente, e pelas mães se encontrarem instáveis emocionalmente e em um ambiente diferente.

Também foi possível perceber as facilidades, como o acesso livre das mães à UTIN, a filosofia 
institucional por ser hospital Amigo da Criança, a atuação do banco de leite por fornecer o leite humano para os RN cujas mães não conseguiram extrair o volume total de leite, e por estimular a extração manual, garantindo o estímulo da produção láctea.

Não obstante a presença do fonoaudiólogo não ter sido muito abordada pelas mães, alguns profissionais reconheceram esse ponto como uma facilidade, uma vez que são esses que acompanham e preparam a passagem de outras formas de aleitamento para a amamentação ao seio materno, estimulando a sucção e a deglutição dos bebês.

Sugere-se que algumas intervenções são necessárias, no sentido de aprimorar e/ou implementar a prática do aleitamento materno no contexto da UTIN ou de outros setores de assistência ao binômio mãe-filho.

É importante abordar esse assunto específico nas graduações em saúde, para que os futuros profissionais tenham conhecimento dessa prática e de quais maneiras ela pode acontecer, estando, assim, capacitados adequadamente para realizá-la e orientar as mães nesse processo. Também é fundamental o preparo profissional para trabalhar com a temática e para que as informações sejam transmitidas mais adequadamente para as mães, não só na UTIN, mas também durante o pré-natal, a fim de obter resultados mais positivos quanto à realização dessa prática nesse setor.

Dessa forma, sugere-se a formação de Grupo de Mães no contexto da UTIN, para abordar vários assuntos, dentre eles o Aleitamento Materno, o que possibilitará incluir as mães de forma mais ativa e efetiva como sujeitos no internamento do filho.

\section{Colaborações:}

1 - concepção, projeto, análise e interpretação dos dados: Aisiane Cedraz Morais e Siena Nogueira Guirardi;

2 - redação do artigo e revisão crítica relevante do conteúdo intelectual: Aisiane
Cedraz Morais, Siena Nogueira Guirardi e Juliana de Oliveira Freitas Miranda;

3 - aprovação final da versão a ser publicada: Aisiane Cedraz Morais, Siena Nogueira Guirardi e Juliana de Oliveira Freitas Miranda.

\section{Referências}

1. Grummer-Strawn LM, Rollins N. Summarising the health effects of breastfeeding. Acta Paediatr. 2015;104(467):1-2. DOI: 10.1111/apa.13136

2. Conceição CM, Coca KP, Alves MR, Almeida FA. Validação para língua portuguesa do instrumento de avaliação do aleitamento materno LATCH. Acta Paul Enferm. 2017;30(2):210-16. DOI: http:// dx.doi.org/10.1590/1982- 0194201700032

3. Brasil. Secretaria de Atenção à Saúde. Departamento de Atenção Básica. Saúde da criança: aleitamento materno e alimentação complementar [Internet]. Brasília (DF); 2015 [cited 2019 Oct 28]. (Cadernos de Atenção Básica, no 23). Available from: \&lt;http://bvsms.saude.gov.br/bvs/ publicacoes/saude_crianca_aleitamento_materno_ cab23.pdf\&gt;

4. Santos TAS, Dittz ES, Costa PR. Práticas favorecedoras do aleitamento materno ao recémnascido prematuro internado na unidade de terapia intensiva neonatal. Rev Enferm Cent O Min. 2012;2(3):438-50. DOI: http://dx.doi.org/10.19175/ recom.v0i0.220.

5. Rodrigues AP, Padoin SMM, Paula CC, Guido LA. Fatores que interferem na autoeficácia da amamentação: revisão integrativa. Rev enferm UFPE on line. 2013;7(5):4144-52. DOI: 10.5205/ reuol.4134-32743-1-SM-1.0705esp201307

6. Amando AR, Tavares AK, Oliveira AKP, Fernandes FECV, Sena CRS, Melo RA. Percepção de mães sobre o processo de amamentação de recém-nascidos prematuros na Unidade Neonatal. Rev baiana enferm. 2016 out-dez;30(4):1-11. DOI: http://dx.doi.org/10.18471/rbe.v30i4.17134

7. Minayo MCS. O desafio do conhecimento: pesquisa qualitativa em saúde. 12a ed. São Paulo: Hucitec: Abrasco; 2010.

8. Bardin L. Análise de conteúdo. Lisboa: Edições 70; 1977.

9. Brasil. Ministério da Saúde. Conselho Nacional de Saúde. Resolução n. 466/2012. Aprova diretrizes e normas regulamentadoras de pesquisas envolvendo seres humanos [Internet]. Brasília (DF); 
2012 [cited 2019 Oct 28]. Available from: http:// www.conselho.saude.gov.br/web_comissoes/ conep/index.html

10. Costa MCG, Arantes MQ, Brito MDC. A UTI neonatal sob a ótica das mães. Rev Elet Enferm. 2010;12(4):698-704. DOI: 10.5216/ree.v12i4.7130

11. Freitas BAC, Lima LM, Carlos CFLB, Priore SE, Franceschini SCC. Duração do aleitamento materno em prematuros acompanhados em serviço de referência secundário. Rev paul pediatr. 2016;34(2):189-96. DOI: https://doi.org/10.1016/j. rpped.2015.10.005

12. Schanler RJ. Outcomes of human milk-fed premature infants. Semin Perinatol. 2011;35(1):29-33. DOI: https://doi.org/10.1053/j. semperi.2010.10.005

13. Brasil. Secretaria de Atenção à Saúde. Departamento de Atenção Básica. Saúde da criança: Nutrição infantil: aleitamento materno e alimentação complementar [Internet]. Brasília (DF); 2009 [cited 2019 Oct 29]. Available from: http://bvsms.saude. gov.br/bvs/publicacoes/saude_crianca_nutricao_ aleitamento_alimentacao.pdf

14. Ichisato SMT, Shimo AKK. Vivência da amamentação: lactogogos e rede de suporte [Internet]. Ciênc Cuid Saúde. 2006 [cited 2019 Oct 29];5(3):355-62. Available from: http:// www.periodicos.uem.br/ojs/index.php/ CiencCuidSaude/article/view/5052/3258.

15. Hernandes TA, Fujinami AN, Raimundo EC, Cardoso CP, Higa EFR, Lazarini CA. Significado e dificuldades da amamentação: representação social das mães. Rev Psicol Divers Saúde. 2017 nov;6(4):247-57. DOI: 10.17267/2317-3394rpds. v6i4.1692

16. Melo LM, Machado MMT, Leite AJM, Rolim KMC. Prematuro: experiência materna durante amamentação em unidade de terapia intensiva neonatal e pós-alta. Rev Rene. 2013 [cited 2019 Oct 28];14(3):512-20. Available from: http://periodicos. ufc.br/rene/article/view/3423
17. Pessoa-Santana MCC, Silveira BL, Santos ICS, Mascarenhas MLVC, Dias PGC. Métodos Alternativos de Alimentação do Recém-Nascido Prematuro: Considerações e Relato de Experiência. Rev bras ciênc saúde. 2016;20(2):157-162. Available from: http://www.periodicos.ufpb.br/ojs/index. $\mathrm{php} / \mathrm{rbcs} /$ article/view/14607

18. Siqueira MBC, Dias MAB. A percepção maternal sobre vivência e aprendizado de cuidado de um bebê prematuro. Epidemiol Serv Saúde. 2011 jan-mar;20(1):27-36. DOI: 10.5123/S167949742011000100004

19. Bezerra MJ, Carvalho ACO, Sampaio KJAJ, Damasceno SS, Oliveira DR, Figueiredo MFER. Percepção de mães de recém-nascidos prematuros hospitalizados acerca da amamentação. Rev baiana enferm. 2017;31(2):1-9. DOI: 10.18471/rbe. v31i2.17246

20. World Health Organization. Ten steps to successful breastfeeding [Internet]. Geneva (CH); 2019 [cited 2019 Nov 5]. Available from: https://www.who.int/ nutrition/bfhi/ten-steps/en/

21. World Health Organization. Implementation guidance: protecting, promoting and supporting breastfeeding in facilities providing maternity and newborn services - the revised Babyfriendly Hospital Initiative [Internet]. Geneva (CH); 2018 [cited 2019 Nov 5]. Available from: https://apps.who.int/iris/bitstream/handle/ 10665/272943/9789241513807-eng.pdf

22. Brasil. Secretaria de Atençãoà Saúde. Departamento de Ações Programáticas Estratégicas. Iniciativa Hospital Amigo da Criança. Área técnica de saúde da criança e aleitamento materno [Internet]. Brasília (DF); 2011 [cited 2019 Nov 5]. Available from: http://bvsms.saude.gov.br/bvs/publicacoes/ iniciativa_hospital_amigo_crianca.pdf

Recebido: 26 de fevereiro de 2020

Aprovado: 27 de março de 2020

Publicado: 30 de abril de 2020

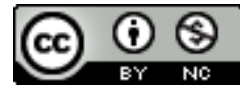

A Revista Baiana de Enfermagem utiliza a Licença Creative Commons - Atribuição-NãoComercial 4.0 Internacional. https://creativecommons.org/licenses/by-nc/4.0/ Este artigo é de acesso aberto distribuído sob os termos da Licença Creative Commons (CC BY-NC).

Esta licença permite que outros remixem, adaptem e criem a partir do seu trabalho para fins não comerciais. Embora os novos trabalhos tenham de lhe atribuir o devido crédito e não possam ser usados para fins comerciais, os usuários não têm de licenciar esses trabalhos derivados sob os mesmos termos. 